\title{
SOME ASPECTS OF DYNAMIC RIVETING SIMULATIONS
}

\author{
Elżbieta Szymczyk, Jerzy Jachimowicz, Krzysztof Puchała
}

\author{
Military University of Technology \\ Department of Mechanics and Applied Computer Science \\ Gen. Sylwestra Kaliskiego Street 2, 00-908 Warsaw, Poland \\ tel.: +4822 6839039, fax: +48226839355 \\ e-mail:eszymczyk@wat.edu.pl
}

\begin{abstract}
Riveting is a commonly used (especially in aircraft structures) method of joining metal and composite components. The methods of forming solid shank rivets can be classified in two types: static and dynamic. The static method is the most efficient one. Regrettably, its application is limited. A popular upsetting tool used in an aircraft is a pneumatic riveter. The rivet driving requires a few hammer strokes.

The total stress in a riveted joint depends on the residual and applied stress. Residual post-riveting stress fields are widely accepted to have a beneficial influence on the fatigue life of aircraft structures. The analysis is carried out for a solid mushroom rivet (made of PA25 alloy) joining two sheets (made of 2024T3 alloy). Nonlinear dynamic simulations of the upsetting process are carried out. Simulation of the riveting process is significantly influenced by a material model.

The numerical calculations are performed for three different cases of upsetting described by the formed rivet head diameters $1.4 d, 1.5 d$ and $1.6 d$, respectively. The rivet head diameter and, consequently, the residual stress state depend on hammer stroke energy. It has a significant influence on a plastic region around the rivet hole, whereas the influence of a number of strokes can be neglected.

The strain rate in both local and global (average) formulation is analysed in the paper. For one hammer stroke, the global strain rate of the rivet shank is about 1.0 thousand per second. The local strain rate is about two times greater than the global one, so a strain rate factor has an effect on the residual stress state. For a few hammer strokes, the strain rate is lower than for one stroke; however, it increases a little in each stroke. The hole deformation can be treated as a function of the internal energy of the sheet. The lower total energy of the part the greater influence of the strain rate on the internal energy is observed.
\end{abstract}

Keywords: riveting, dynamic simulation, residual stress state

\section{Introduction}

Riveting is a traditional but still popular method of joining metal and composite components especially in aircraft [1-6]. Aircraft structures, like airplane fuselages and wings, are thin-walled ones stiffened with stringers, frames or ribs. Sheets are typically assembled by multiple riveted or bolted joints. Rivets and bolts are also used to join sheets and stiffeners. Therefore, fatigue resistance of the aircraft structure depends on thousands riveted joints used to build it.

The methods of driving solid shank rivets can be classified in two types: static and dynamic. The static (squeeze) method is the most efficient one since it causes that all the rivets are driven with uniform pressure and the rivet shank is sufficiently and regularly expanded to fill completely the rivet hole. Regrettably, the application of this method is limited.

The most common upsetting tool used in an aircraft is the pneumatic hammer (so called rivet gun). The shank's end is driven and the manufactured head is bucked. This method is called reverse riveting. The rivet driving requires a few hammer strokes.

The riveted joints are critical areas of the aircraft structure due to severe stress concentrations, plastic strain and secondary bending as well as micro-local effects such as surface damage (fretting wear). These phenomena cause fatigue crack initiation at the rivet holes or between the sheets, which propagate and decrease fatigue resistance of the riveted joint [2, 7-10]. 
The total stress experienced by the material at a given location within a component depends on the residual stress and applied load. Residual post-riveting stress fields are widely accepted to have a significant influence on the fatigue life of aircraft structures. Especially, a compressive uniform residual stress state (Fig. 1a) can be beneficial because it tends to decrease probability of stress corrosion and fatigue cracking $[2,7,9]$.

If stroke energy is large enough then compression in hoop direction occurs, and it has an influence on a crack nucleation place and a fatigue crack path. Comparison of static and fatigue crack paths in riveted joint shows that the later one is longer (Fig. 1b).

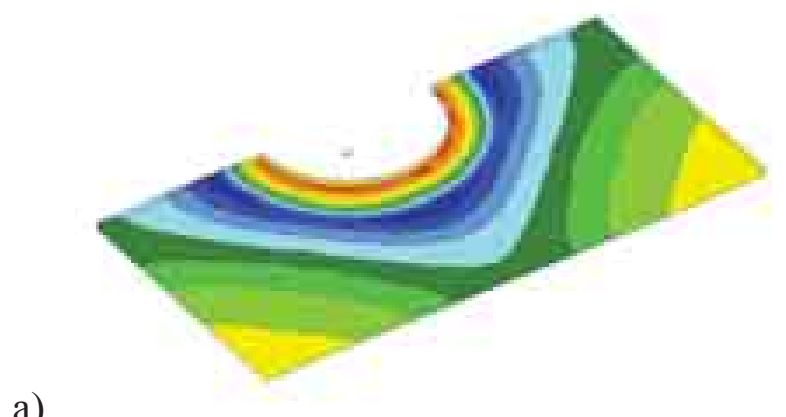

a)

b)

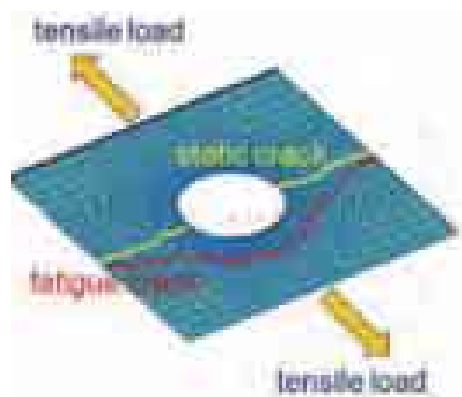

\begin{tabular}{|l|l|l|l|l|l|l|l|l|l|l|l}
\hline 77 & 60 & 43 & 27 & 10 & -6 & -22 & -40 & -56 & -72 & -90 & -105
\end{tabular}

Fig. 1. Hoop stress field a) and fatigue crack path b)

Numerical simulations of riveting process are performed. Deformation, internal energy, plastic strain and strain rate are considered. Additional results connected with this type of connection are presented in papers [11-13].

\section{Numerical model}

The analysis is carried out for the solid mushroom rivet (shank diameter $\mathrm{d}=3.5 \mathrm{~mm}$ ) joining two aluminium sheets (thickness $\mathrm{g}=1.2 \mathrm{~mm}$ ). The three-dimensional numerical model of the $10.5 \mathrm{~mm}$ wide neighbourhood of a single rivet is considered. The following dimensions of the mushroom rivet are assumed: head radius $R_{f}=4.2 \mathrm{~mm}$, head diameter $D_{f}=7 \mathrm{~mm}$, head height $\mathrm{h}_{\mathrm{f}}=1.88 \mathrm{~mm}$, shank length $\mathrm{H}=4.2 \mathrm{~mm}$ and nominal gap $\rho=0.05 \mathrm{~mm}$ (Fig. 2a).

The rivet and sheets models consist of eight-nodded, isoparametric, three-dimensional fully integrated brick elements with a tri-linear interpolation function. The tools (hammer and bucking bar) are described as rigid surfaces. The bucking bar is fixed and the hammer is moved with initial kinetic energy. The local model of a riveted joint is made with Patran (Fig. 2b).

a)

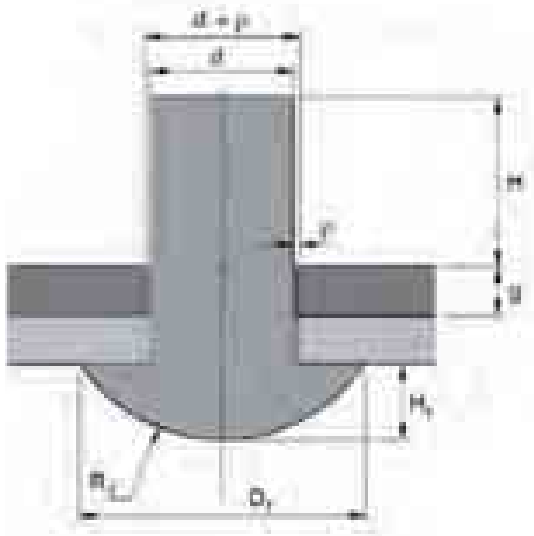

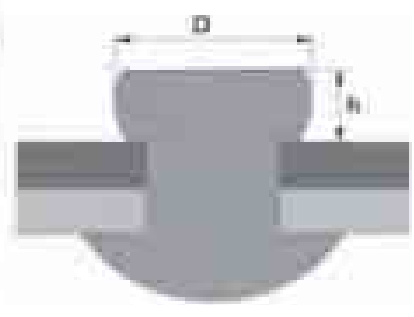

b)

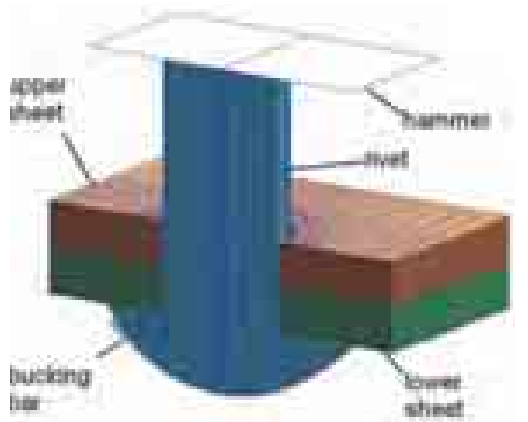

Fig. 2. Rivet dimensions a) and model of the mushroom rivet b) 
The equation of motion is solved using an explicit central difference scheme. It is an effective method in dynamic nonlinear calculations including large strains but time step should be small enough. Nonlinear dynamic simulation of the upsetting process is carried out using the Lsdyna code.

The local model geometry consists of three solids: the rivet and two sheets, whereas FE mesh contains about 90000 eight-node, isoparametric, three-dimensional fully integrated brick elements with a tri-linear interpolation function, 8-point volume integration allows avoiding hourglassing.

Nonlinearities in our analysis are due to elasto-plastic material behaviour and contact with friction between mating surfaces of collaborating parts of the joint. Then stress divergence and load vectors are nonlinear but in an explicit procedure, they can be changed in every time step.

The sheets are made of $2024 \mathrm{~T} 3$ aluminium alloy and the rivet is made of PA25 alloy. Simplified Johnson Cook material model (1) is used in calculations. The yield stress for the multiaxial state is calculated using the von Mises criterion. Elastic-plastic stress - strain curves are presented in Fig. 3.

$$
\sigma=\left(\mathrm{A}+\mathrm{B} \varepsilon_{\mathrm{p}}^{\mathrm{n}}\right)\left(1+\mathrm{C} \ln \left(\dot{\varepsilon}_{\mathrm{p}}^{*}\right)\right),
$$

where:

$\mathrm{A}=374(318) \mathrm{MPa}$,

$\mathrm{B}=420(450) \mathrm{MPa}$,

$\mathrm{C}=0.01(0.0083)$

$\mathrm{n}=0.42-$ parameters of sheet (rivet) material model,

$\varepsilon_{\mathrm{p}}-$ plastic strain,

$\dot{\varepsilon}_{p}^{*}-$ plastic strain rate.

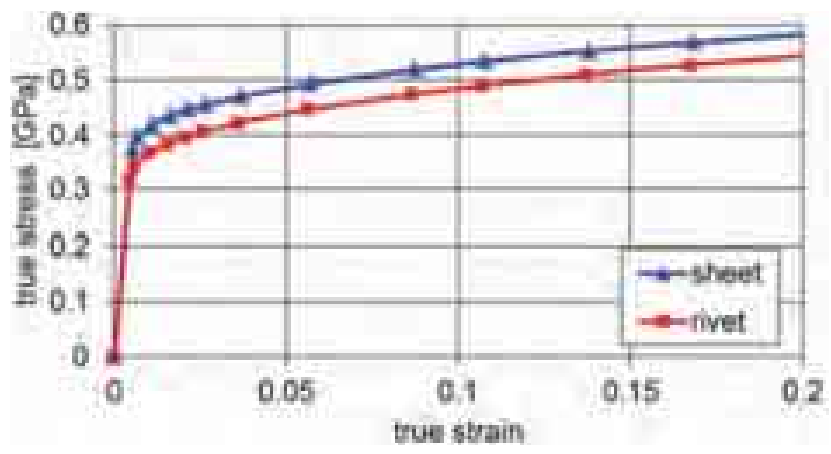

Fig. 3. Stress-strain curve

Contact with Coulomb friction model $(\mu=0.2)$ is applied at a contact interface. The segment based penalty formulation is applied to numerical implementation of the contact constraints. The interface force is a product of the contact stiffness and the penetration value. Frictional force depends on the stiffness of the master segment and it works in a different way on a rigid and deformable boundary.

Viscous contact damping is used because it works effectively in removing high frequency noise in problems, which involve the impact.

\section{Analysis of riveted joint}

The numerical calculations are performed for three different cases of upsetting described by the initial kinetic energy of the hammer $\mathrm{E}=15,18.5$ and $22 \mathrm{~J}$, respectively. The formed rivet head diameter depends on hammer stroke energy. The nominal rivet head diameter $\mathrm{D}$ is equal to one and half shank diameter $\mathrm{d}$ and the tolerance limits specified in manufacturing instruction of riveting are $\pm 10 \%$ of shank diameter.

The riveting process can be described by a force-displacement curve. A strain rate influence on this process is shown in Fig. 4. The increase of strain rate factor c causes the increase in the rivet stiffness, however it is rather a small change. 


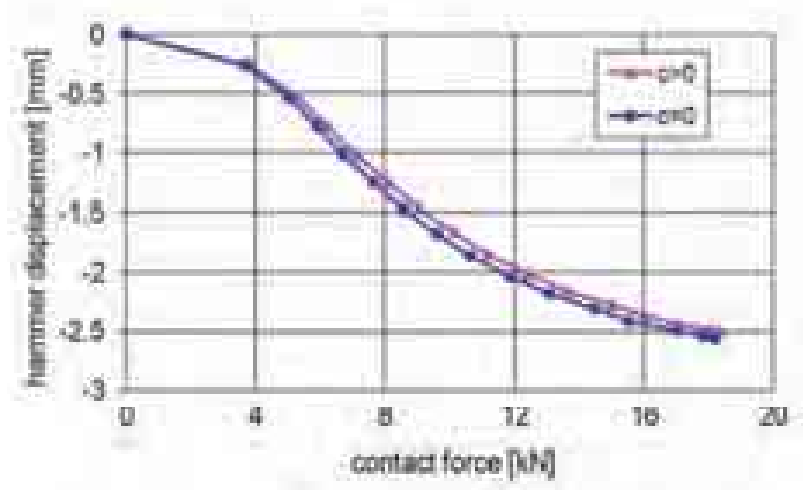

Fig. 4. Force-displacement curve for hammer energy $E$ $=22 \mathrm{~J}$

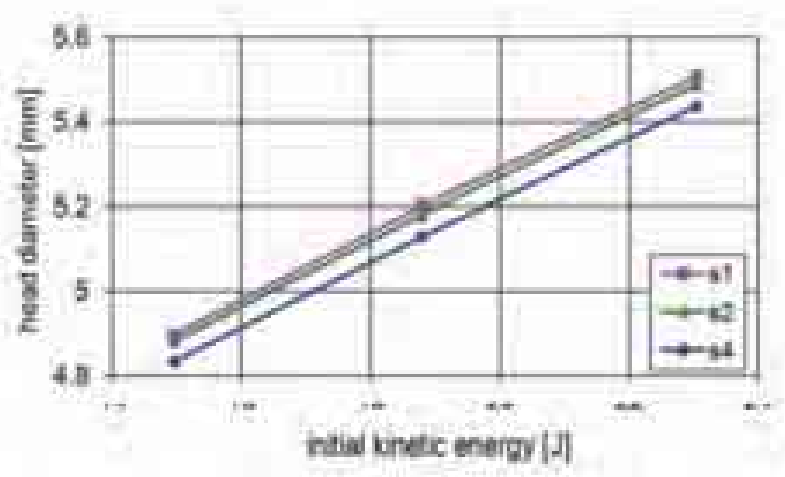

Fig. 5. Driven rivet head diameter vs. initial energy

The rivet head diameter increases with the initial stroke energy (Fig. 5), however, it decreases a little with a number of strokes (s1, s2 and s4 means one, two and four strokes, respectively). The strain rate factor has an influence on the rivet head diameter, which decreases by about $5 \%$ when a strain rate increases (Fig. 6).

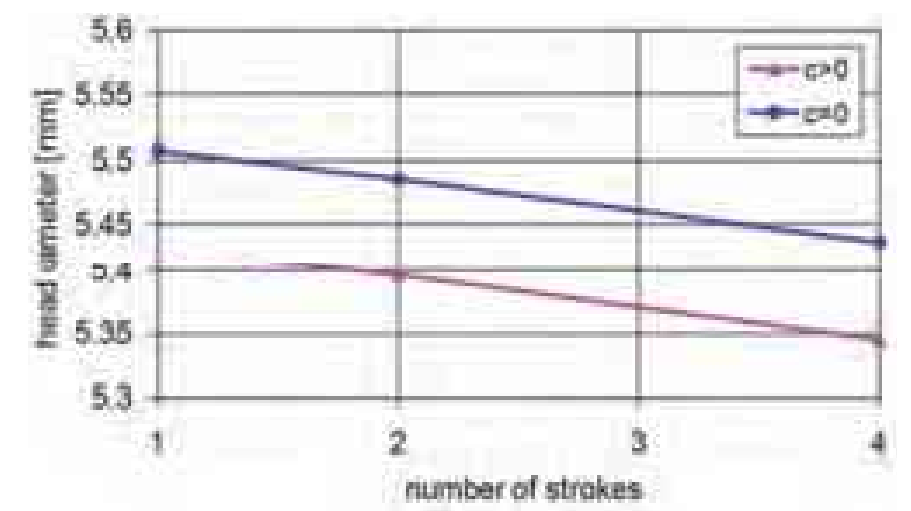

Fig. 6. Driven rivet head diameter vs. number of strokes for initial energy $E=22 \mathrm{~J}$

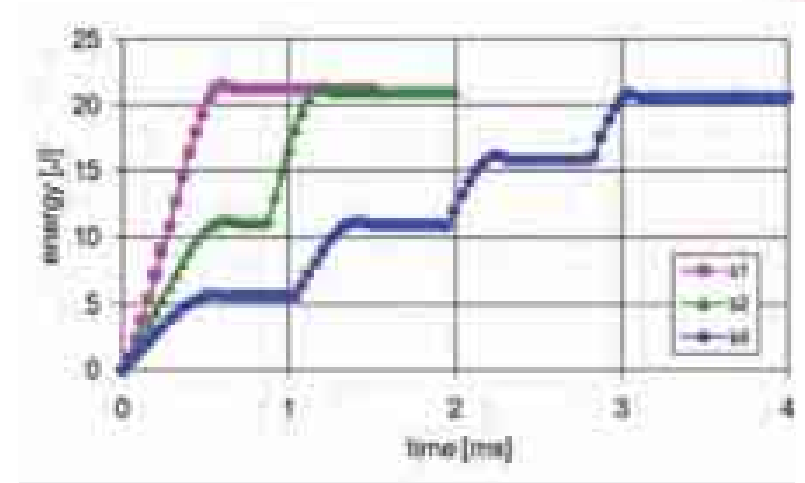

Fig. 7. Internal energy of the rivet for initial energy $E=22 J$

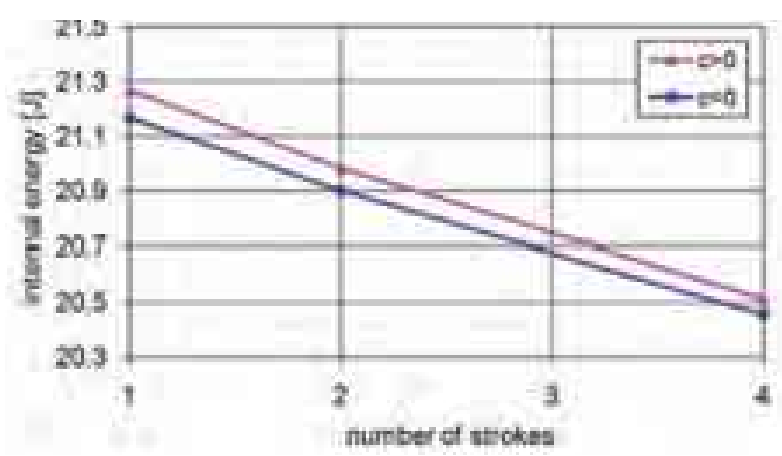

Fig. 8. Strain rate influence on the rivet internal energy

The rivet absorbs almost all kinetic energy $(22 \mathrm{~J})$ of the stroke (Fig. 7). When a number of strokes increases also total time of the riveting increases.

Despite the rivet head diameter decreases, about 5\% with a strain rate (Fig. 6) (when a strain rate factor c increases), the rivet internal energy increases a little (Fig. 8), it can be even concluded that internal energy does not change. 


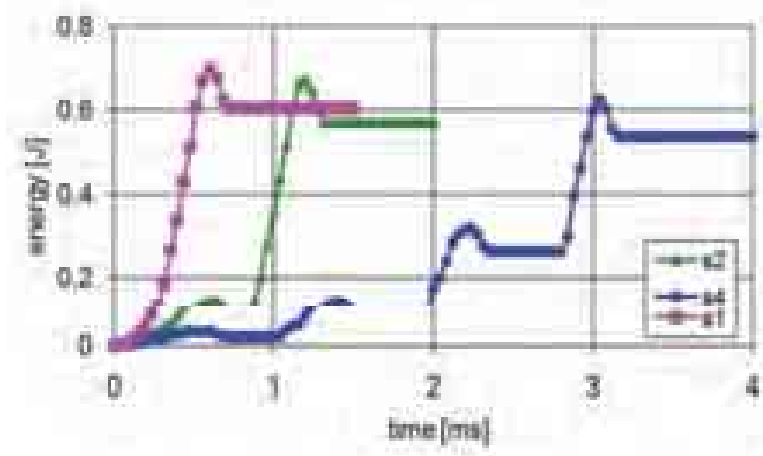

Fig. 9. Internal energy of the upper sheet for initial energy $E=22 \mathrm{~J}$

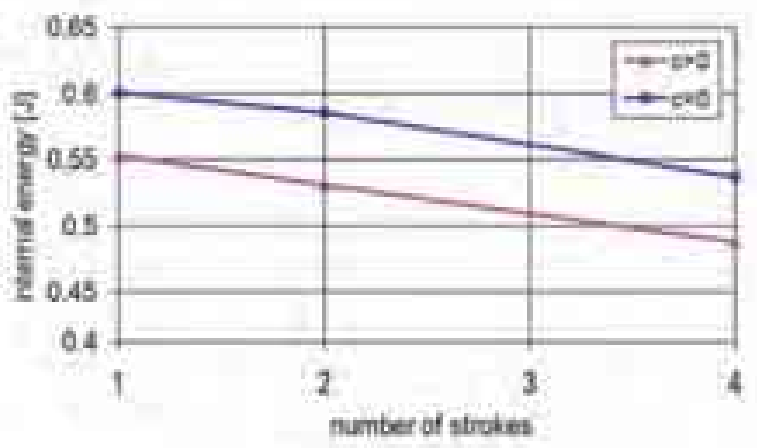

Fig. 10. Strain rate influence on the upper sheet internal energy

The internal energy of the sheet can be treated as a function of the hole deformation. The internal energy of the upper sheet for initial energy 22J is presented in Fig. 9.

The strain rate causes that upper sheet internal energy decreases by about $8 \%$ (Fig. 10). Having a look at internal energy of the lower sheet, it is evident that reversible elastic energy is a substantial part of the total lower sheet energy (Fig. 11).

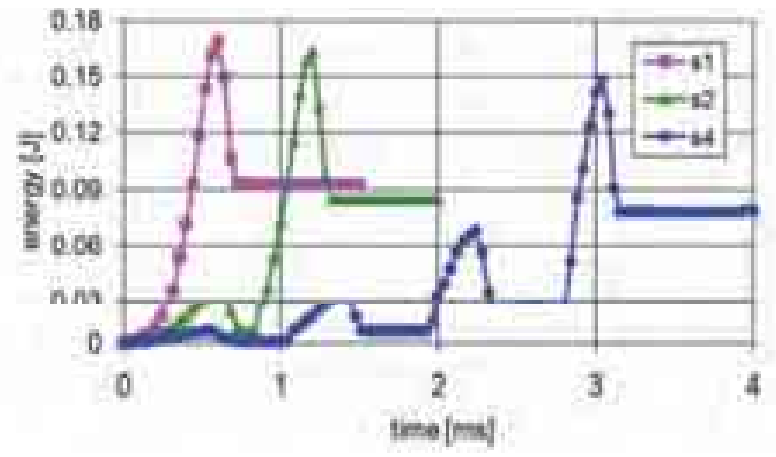

Fig. 11. Internal energy of the lower sheet for initial energy $E=22 \mathrm{~J}$

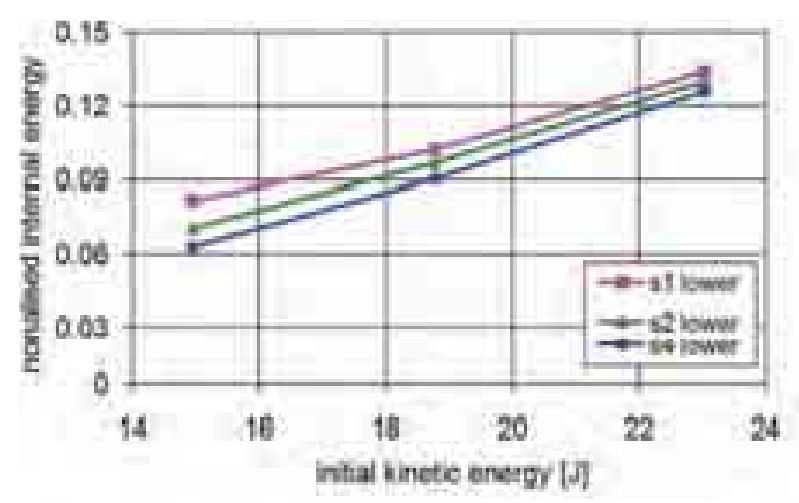

Fig. 13. Normalised internal energy of the lower sheet

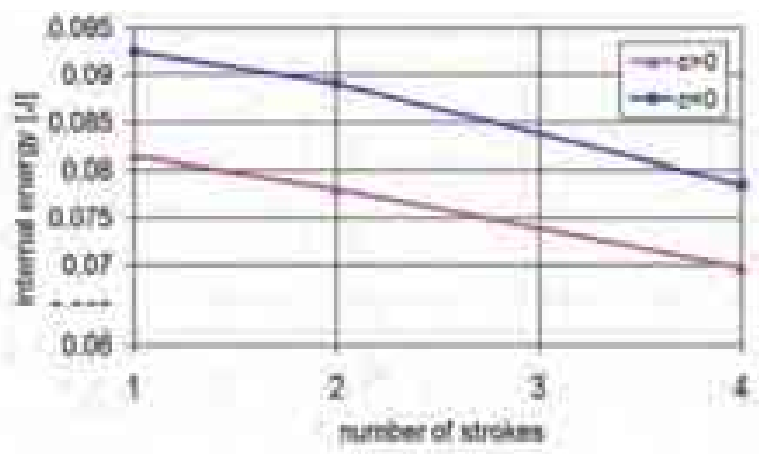

Fig. 12. Strain rate influence on the lower sheet internal energy

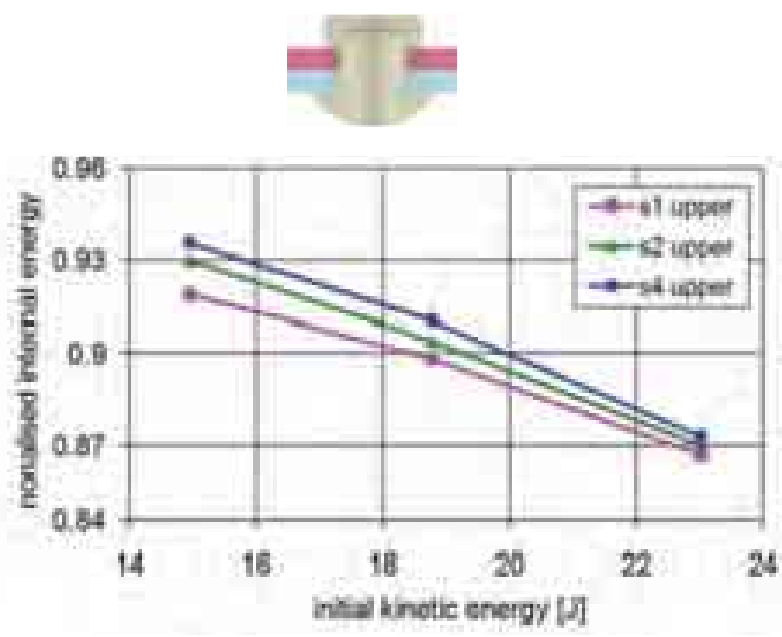

Fig. 14. Normalised internal energy of the upper sheet 
The strain rate decreases lower sheet internal energy by about 14\% (Fig. 12). Therefore, the influence of the strain rate factor on internal energy of selected parts of the joint is as follows: the lower total energy of the part the larger influence of the strain rate is observed.

Generally speaking, internal energy of the joint decreases when a number of strokes increases, normalised internal energy of the sheets (energy of the sheets to energy of the joint) also decreases with a number of strokes likewise normalised internal energy of the lower sheet (energy of the lower sheet to energy of two sheets) (Fig. 13). However, normalised internal energy of the upper sheet (energy of the upper sheet to energy of two sheets) increases with a number of strokes (Fig. 14). The increase in the initial energy causes: the increase in relative energy of the lower sheet and the decrease it in the upper one.

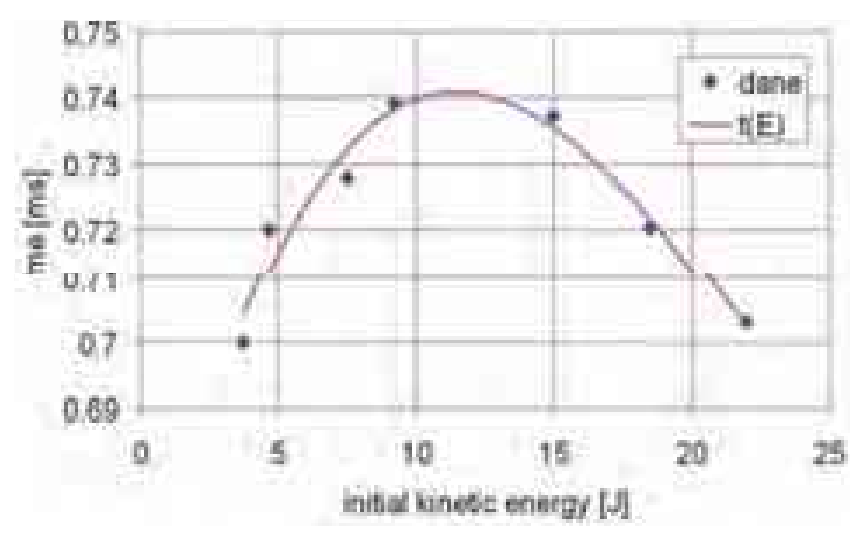

Fig. 15. Time of a single stroke

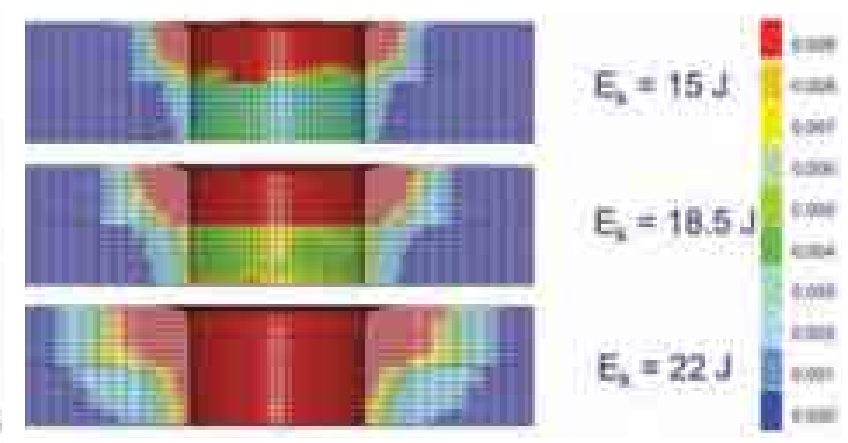

Fig. 16. Plastic deformation

The time of a single stroke is a nonlinear function of initial kinetic energy (Fig. 15). For a rivet shank $3.5 \mathrm{~mm}$, the maximum time is achieved when initial energy is about $11 \mathrm{~J}$.

Irreversible plastic deformations of the sheet material around the rivet hole remain after the riveting process. Plastic strain regions are analysed for various kinetic energies (Fig. 16) and for various number of strokes. Initial energy has a significant influence on a plastic region, whereas an influence of a number of strokes can be neglected. The hole in the upper sheet (from the side of the driven rivet head) is better filled with the rivet material than in the lower one.

The strain rate in a local (2) and global average (3) formulation are analysed:

$$
\begin{gathered}
\dot{\varepsilon}_{p}=\frac{d \varepsilon_{p}}{d \mathrm{t}}=\sqrt{\frac{2}{3} \dot{\varepsilon}_{i j}^{p} \dot{\varepsilon}_{i j}^{p}} . \\
\frac{\Delta \varepsilon}{\Delta \mathrm{t}}=\left|\frac{\Delta \mathrm{h}}{\mathrm{h} \Delta \mathrm{t}}\right|=\left|\frac{\mathrm{h}(\mathrm{t}+\Delta \mathrm{t})-\mathrm{h}(\mathrm{t})}{\mathrm{h}(\mathrm{t}) \Delta \mathrm{t}}\right| .
\end{gathered}
$$

where:

$\dot{\varepsilon}_{i j}^{p}-$ plastic strain tensor rate,

$\Delta \mathrm{t}$ - time step,

$\mathrm{h}-$ driven rivet head height,

t - time.

The global strain rate changes from 1.5 thousand to two thousand per second for one hammer stroke (Fig. 17). The local strain rate (blue line) is about two times greater than the global one (pink line). The hammer releasing causes a peak on the strain rate graph. A peak value is small for the global strain rate but large for the local one. For a few hammer strokes the strain rate increases a little in each stroke (Fig. 18). 


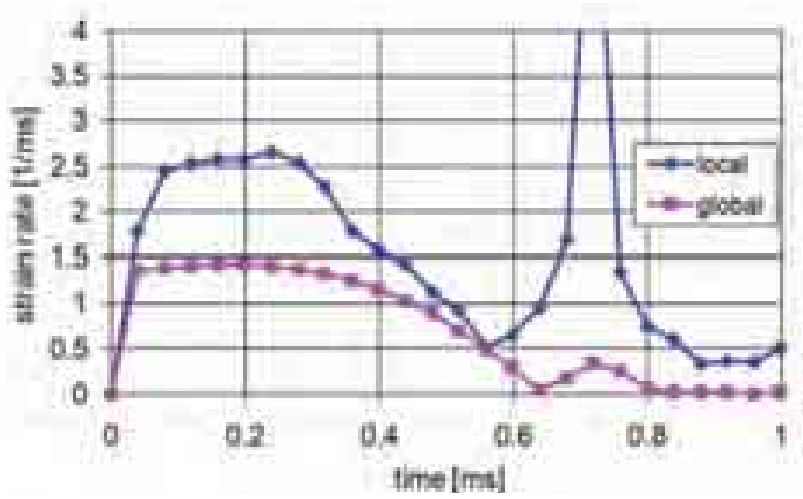

Fig. 17. Strain rate for a single stroke

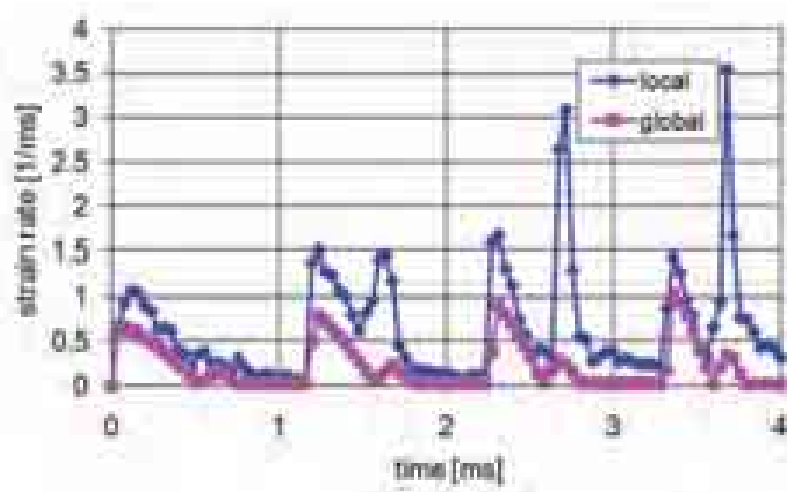

Fig. 18. Strain rate for a few strokes

\section{Conclusions}

Simulation of the riveting process is significantly influenced by material and contact models.

The rivet head diameter and, consequently, the residual stress state depend on hammer stroke energy. It has a significant influence on a plastic region around the rivet hole, whereas the influence of a number of strokes can be neglected. The residual strain and stress fields in the joint are practically independent on the riveting method (static or dynamic).

Despite the average strain rate of the rivet which is about $1000 / \mathrm{s}$, a strain rate factor has a minor effect on the rivet head diameter and the sheets energy (deformation) as well as the residual strain/stress state. For a few hammer strokes, the strain rate is lower than for one stroke, however, it increases a little in each stroke.

The hole deformation can be treated as a function of the internal energy of the sheet. The lower total energy of the part the greater influence of the strain rate on the internal energy is observed. The hole in the upper sheet (from the side of the driven rivet head) is better filled with the rivet material than in the lower one.

The increase in the stroke energy causes the increase in relative energy of the lower sheet.

\section{References}

[1] Langrand, B., Patronelli, L., Deletombe, E., Markiewicz, E., Drazétic, P., An alternative numerical approach for full scale characterization for riveted joint design, Aerospace Science and Technology, 6, pp. 343-354, 2002.

[2] Rijck, J., Stress Analysis of Fatigue Cracks in Mechanically Fastened Joints, Doctoral Dissertation, Delft University of Technology, 2005.

[3] Rans, C. D., The Role of Rivet Installation on the Fatigue Performance of Riveted Lap Joints, Doctoral Dissertation, Department of Mechanical and Aerospace Engineering Carleton University, 2007.

[4] Brown, A. M., Straznicky, P. V., Simulating fretting contact in single lap splices, International Journal of Fatigue, 31, pp. 375-384, 2009.

[5] Kaniowski, J., Wronicz, W., Jachimowicz, J., Szymczyk, E., Methods for FEM analysis of riveted joints of thin-walled aircraft structures within the IMPERJA Project, 31st Conference and the 25th Symposium of the International Committee on Aeronautical Fatigue (ICAF), Rotterdam 2009.

[6] Bedair, O., Stress field characteristics of eccentrically loaded aircraft spliced joints, Applied Mathematical Modelling, 2011.

[7] Bröcker, W., Buderath, M., Fatigue Damages During Tornado MAF Test, AGARD Specialists Meeting on Widespread Fatigue Damage in Military Aircraft, Rotterdam, 10-11 May 1995. 
[8] Skorupa, M., Skorupa, A., Machniewicz, T., Korbel, A., An experimental investigation on the fatigue performance of riveted lap joints, 25th Symposium of the International Committee on Aeronautical Fatigue (ICAF), Rotterdam 2009.

[9] Skorupa, A., Skorupa, M., Effect of Production and Design Related Factors on the Fatigue Behavior of Riveted Joint in Aircraft Fuselage, Fatigue of Aircraft Monographic Series. Institute of Aviation Scientific Publication, Warsaw, Poland 2010.

[10] Szymczyk, E., Jachimowicz, J., Derewońko, A., Sławiński, G., Analysis of microslips and friction in the riveted joint, Solid State Phenomena, 165, 388-393, 2010.

[11] Szymczyk, E., Jachimowicz,J., Sławiński, G., Riveting process simulation - upsetting of the mushroom rivet, Journal of KONES, Vol. 15, No. 2, pp. 493-502, Warszawa 2008.

[12] Szymczyk, E., Sławinski, G., Jachimowicz, J., Dynamic simulations of the riveting process, Workshop 2009 Theoretical and experimental approaches for dynamic industrial processes, Madrid, Leganés 2009.

[13] Szymczyk, E., Sławiński, G., Influence of material model on tensile loaded joint, Solid State Phenomena, 165, 394-399, 2010. 